\title{
Synthesis of High Refractive Index Poly(thioether sulfone)s with High Abbe's Number Derived from 2,5-Bis(sulfanylmethyl)-1,4-dithiane
}

\author{
By Yasuo SUZUKI, Tomoya HIGASHIHARA, Shinji ANDO, and Mitsuru UEDA*
}

Two kinds of new thermoplastic poly(thioether sulfone)s (PESs) with high refractive indices and high Abbe's numbers have been developed by the simultaneous introduction of sulfide, sulfone, and alicyclic units in the polymer chains. The PESs with high molecular weights were prepared by Michael polyaddition of 2,5-bis(sulfanylmethyl)-1,4-dithiane (BMMD) with divinyl sulfone (DVS) or bis(vinylsulfonyl)methane (BVSM). Tough, flexible, and transparent amorphous PES (poly(BMMD-DVS)) film was obtained, and showed good thermal stability with the 5\% weight-loss temperature of $303{ }^{\circ} \mathrm{C}$ in nitrogen, the glass transition temperature of $47^{\circ} \mathrm{C}$, and the melting point of $174{ }^{\circ} \mathrm{C}$. Poly(BMMD-DVS) and poly(BMMD-BVSM) exhibited the highest level of the refractive indices of 1.6512 and 1.6461, and the Abbe's numbers of 42.6 and 43.1 as thermoplastics.

KEY WORDS: Thermoplastics / Refractive Index / Abbe's Number / Poly(thioether sulfone) /

The progress of advanced optical devices is becoming significantly dependent on the availability of new functional materials. ${ }^{1-3}$ Recently, high refractive index $\left(n_{\mathrm{D}}\right)$ polymers with high Abbe's numbers $\left(v_{\mathrm{D}}\right)$ have been widely proposed for microoptic and optoelectronic applications, such as lenses, prisms, waveguides, and diffractive gratings. ${ }^{4,5}$ The advantage of polymers is their processability, good impact resistance, and light weight compared to inorganic glasses. At present, poly(methyl methacrylate), polycarbonate, and cycloolefin polymers ${ }^{6}$ are widely used in camera, pickup, and projector lenses as thermoplastics where injection molding can be applied. On the other hand, thermosetting polymers, such as poly[ethylene glycol bis(allylcarbonate)] (CR-39) ${ }^{7}$ and resins from epysulfides, ${ }^{8}$ polythiols, ${ }^{9}$ and polyisocyanates, ${ }^{10}$ have been applied for consumer use such as eyeglasses, which are manufactured by cast molding. According to the Lorentz-Lorenz theory, the introduction of substituents having high molar refractions and low molar volumes effectively increases the refractive indices of polymers. ${ }^{11}$ With the aid of the high molar refraction of sulfur atoms, various sulfurcontaining high $n_{\mathrm{D}}$ polymers have been developed for thermosets. In addition, the $v_{\mathrm{D}}$, which is the key measure for refractive index dispersion, is also an important parameter for optical materials used in the visible region. Abbe's number is given by

$$
v_{\mathrm{D}}=\left(n_{\mathrm{D}}-1\right) /\left(n_{\mathrm{F}}-n_{\mathrm{C}}\right),
$$

where $n_{\mathrm{D}}, n_{\mathrm{F}}$, and $n_{\mathrm{C}}$ are the refractive indices of a material at the wavelengths of sodium D $(589.3 \mathrm{~nm})$, hydrogen $\mathrm{F}$ (486.1 $\mathrm{nm})$, and hydrogen $\mathrm{C}(656.3 \mathrm{~nm})$ lines, respectively. ${ }^{12} \mathrm{~A}$ high Abbe's number corresponds to a lower dispersion in the refractive index. ${ }^{13}$ It has been reported that highly refractive materials generally exhibit small Abbe's numbers. ${ }^{14}$ Thermoplastics with high values of $n_{\mathrm{D}}$ and $v_{\mathrm{D}}$, however, have so far not been the subject of detailed investigation.

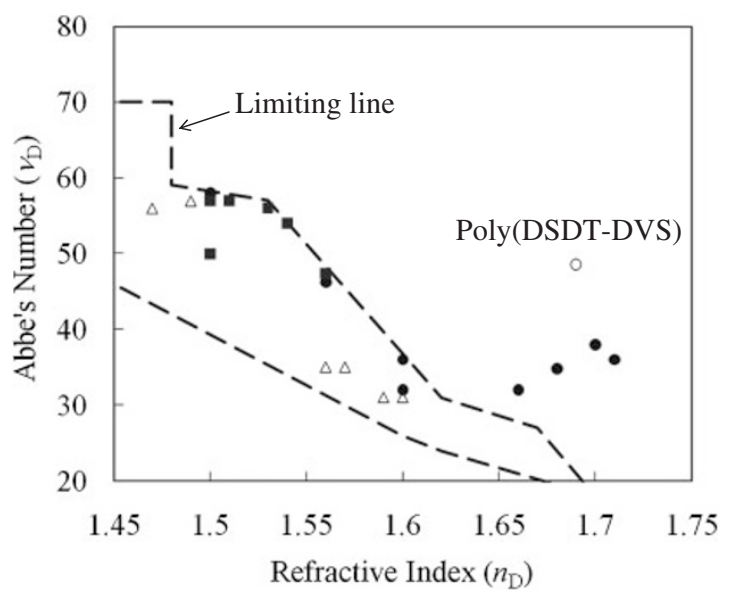

Figure 1. Plastic region in the $n_{\mathrm{D}}-v_{\mathrm{D}}$ diagram. (---) Present limit of the region of transparent plastic. ${ }^{16}(\triangle)$ General-purpose resin for optical materials. ( $\square$ ) Reported thermoplastic with high refractive indices and high Abbe's number. (O) Reported thermosets with high refractive indices and high Abbe's numbers. $(O)$ poly (DSDTDVS).

In a preceding paper, we reported a poly(thioether sulfone) (poly(DSDT-DVS)) with very high $n_{\mathrm{D}}(1.686)$ and $v_{\mathrm{D}}(48.6)$ as thermoplastics by simultaneous introduction of sulfide, sulfone, and alicyclic units in the polymer chains (Figure 1). ${ }^{15}$ However, poly(DSDT-DVS) becomes colored beyond $150{ }^{\circ} \mathrm{C}$ in air, which is probably due to the thermally unstable thioacetal groups. Coloration at elevated temperatures is the major reason why injection molding cannot be applied to poly(thioether sulfone).

To overcome this problem, a new sulfur-containing alicyclic monomer without thioacetal groups is required. Okubo et al. reported that poly $(S$-alkylcarbamate) from 2,5-bis(sulfanyl-

Department of Organic and Polymeric Materials, Tokyo Institute of Technology, 2-12-1-H120, O-okayama, Meguro-ku, Tokyo 152-8552, Japan ${ }^{*}$ To whom correspondence should be addressed (Tel: +81-3-57342127, Fax: +81-3-57342127, E-mail: ueda.m.ad @m.titech.ac.jp). 
methyl)-1,4-dithiane (BMMD) and 1,3-bis(isocyanatomethyl)cyclohexane showed high $n_{\mathrm{D}}$ (1.620), high $v_{\mathrm{D}}$ (38.5), and high transparency in the range of $450-900 \mathrm{~nm} .{ }^{17}$ BMMD consists of thioether and alicyclic units without thioacetal groups that might improve the thermal coloration of the resulting polymers while maintaining high $n_{\mathrm{D}}$ and $v_{\mathrm{D}}$.

This article reports the synthesis and properties of novel poly(thioether sulfone)s from BMMD and divinylsulfone (DVS) or bis(vinylsulfonyl)methane (BVSM). Poly(BMMDDVS) and poly(BMMD-BVSM) exhibited no coloration even at $200{ }^{\circ} \mathrm{C}$ in air, whereas Poly(DSDT-DVS) was colored at $150{ }^{\circ} \mathrm{C}$. The formers also show high refractive indices and high Abbe's numbers of $n_{\mathrm{D}}=1.6512$ and $\nu_{\mathrm{D}}=42.6$ (poly(BMMDDVS)) and $n_{\mathrm{D}}=1.6461$ and $\nu_{\mathrm{D}}=43.1$ (poly(BMMDBVSM)).

\section{EXPERIMENTAL}

\section{Materials}

BMMD was prepared according to the reported procedure. ${ }^{16,18}$ Divinylsulfone (DVS, TCI, Japan), bis(vinylsulfonyl)methane (BVSM, TCI, Japan), and the other chemicals were used as received.

\section{Polymer Synthesis}

Synthesis of Poly(BMMD-DVS). To a solution of BMMD $(1 \mathrm{mmol}, 0.212 \mathrm{~g})$ and DVS (1 mmol, $0.118 \mathrm{~g})$ in dimethylsulfoxide (DMSO, $0.5 \mathrm{~mL}$ ) was added a catalytic amount of triethylamine (TEA). The solution was stirred for $3 \mathrm{~h}$ at room temperature. The resulting white paste was poured into methanol. The precipitate was collected to give white powder $(0.319$ g, yield: $96.5 \%)$. IR $\left(\mathrm{KBr}, \mathrm{cm}^{-1}\right): v=2908,1412$ (alkyl $\mathrm{C}-\mathrm{H}), 1319,1111\left(-\mathrm{SO}_{2}-\right) .{ }^{1} \mathrm{H}$ NMR $\left(300 \mathrm{MHz}, \mathrm{DMSO}-d_{6}\right.$, $\left.40{ }^{\circ} \mathrm{C}, \mathrm{ppm}\right): \delta=3.48-3.39(\mathrm{t}, 4 \mathrm{H}), 3.10-2.84$ (m, 14H). Elem. Anal.Calcd for $\mathrm{C}_{10} \mathrm{H}_{18} \mathrm{O}_{2} \mathrm{~S}_{5}$ : C, 36.33; H, 5.49. Found: C, 36.31; H, 5.23.

Synthesis of Poly(BMMD-BVSM). To a solution of BMMD $(1.03 \mathrm{mmol}, 0.218 \mathrm{~g})$ and a catalytic amount of pyridine in DMSO (0.5 mL), BVSM (1.00 mmol, 0.204 g) in DMSO $(0.5 \mathrm{~mL})$ was added dropwise over $1 \mathrm{~h}$. The solution was stirred for $2 \mathrm{~h}$ at room temperature and poured into methanol. The precipitate was collected to give white powder $(0.3505 \mathrm{~g}$, yield; 83\%). IR $\left(\mathrm{KBr}, \mathrm{cm}^{-1}\right): v=2908,1412$ (alkyl C-H), 1319, $1111\left(-\mathrm{SO}_{2}-\right) .{ }^{1} \mathrm{H}$ NMR $\left(300 \mathrm{MHz}, \mathrm{DMSO}-d_{6}, 40{ }^{\circ} \mathrm{C}\right.$, ppm): $\delta=5.50-5.46(\mathrm{~s}, 2 \mathrm{H}), 3.70-3.61(\mathrm{t}, 4 \mathrm{H}), 3.10-2.84(\mathrm{~m}$, 14H). Elem. Anal.Calcd for $\mathrm{C}_{11} \mathrm{H}_{20} \mathrm{O}_{4} \mathrm{~S}_{6}$ : C, 32.33; H, 4.93. Found: C, 32.37; H, 4.70.

\section{Measurements}

FT-IR spectra were obtained on a Horiba FT-720 spectrometer. Solution state ${ }^{1} \mathrm{H}$ NMR spectra were recorded with a Bruker DPX300S spectrometer using DMSO- $d_{6}$ as a solvent and trimethylsilane as the reference $(0 \mathrm{ppm})$. Inherent viscosity was measured using an Ostwald-viscometer (Sibata No. 2) with a $0.5 \mathrm{~g} / \mathrm{dL}$ DMSO solution at $30^{\circ} \mathrm{C}$. Number- and weightaverage molecular weights $\left(M_{\mathrm{n}}\right.$ and $\left.M_{\mathrm{w}}\right)$ were evaluated by gel permeation chromatography (GPC) on a JASCO PU-2080 Plus with two polystyrene gel columns (TSK GELS $\mathrm{GMH}_{\mathrm{HR}}-\mathrm{M}$ ) DMF containing $0.01 \mathrm{M} \mathrm{LiBr}$ was used as a solvent at a flow rate of $1.0 \mathrm{~mL} \cdot \mathrm{min}^{-1}$ calibrated by standard polystyrene samples. UV-vis transmittance spectra were recorded on a JASCO V-560 UV-vis spectrometer in the range $250-800 \mathrm{~nm}$. Thermal analysis was performed on a Seiko EXSTAR 6000 TG/DTA 6300 thermal analyzer at a heating rate of $10^{\circ} \mathrm{C} / \mathrm{min}$ for thermogravimetry (TG) and a Seiko EXSTAR 6000 DSC 6200 at a heating rate of $10^{\circ} \mathrm{C} / \mathrm{min}$ for differential scanning calorimetry (DSC) under nitrogen. Dynamic mechanical thermal analysis (DMA) was performed on PI film specimens (30 mm long, $10 \mathrm{~mm}$ wide, and $65 \mu \mathrm{m}$ thick) on a Seiko DMS 6300 at a heating rate of $2{ }^{\circ} \mathrm{C} / \mathrm{min}$ with a load frequency of $1 \mathrm{~Hz}$ in air. The refractive indices of polymer films were measured at the wavelengths of 486,589 , and $656 \mathrm{~nm}$ by changing monochromatic filters with an Abbe refractometer (Atago, DR-M4). A halogen lamp with high brightness was used as a white light source.

\section{RESUTLS AND DISCUSSION}

\section{Synthesis of Monomer}

BMMD was selected as a monomer having a high sulfur content of $69.6 \mathrm{wt} \%$ with an alicyclic ring structure. BMMD was prepared via three steps as shown in Scheme 1. The reaction of diallyldisulfide and sulfuryl chloride produced 2,5bis(chloromethyl)-1,4-dithiane which was successively converted to BMMD by treatment with thiourea and alkali solution.

The ${ }^{1} \mathrm{H}$ NMR spectrum of BMMD is shown in Figure 2a with the assignment of each resonance. The signals in the range of $1.56-1.65 \mathrm{ppm}$ are assigned to proton $\boldsymbol{a}$. Taking into consideration that both signals observed in the range of 3.083.15 and $3.00-3.08 \mathrm{ppm}$ possess a large coupling constant of $J=13.8 \mathrm{~Hz}$, they could be assigned to protons $\boldsymbol{d}$ and $\boldsymbol{e}$ with germinal coupling constant. The other protons, $\boldsymbol{b}$ and $\boldsymbol{c}$, correspond to the signal in the range of $2.82-2.96 \mathrm{ppm}$. All the signal intensity ratios are consistent with the number of protons. Since negligible scalar coupling between protons $c$ and $\boldsymbol{d}$ and a small coupling constant between protons $\boldsymbol{c}$ and $\boldsymbol{e}$,
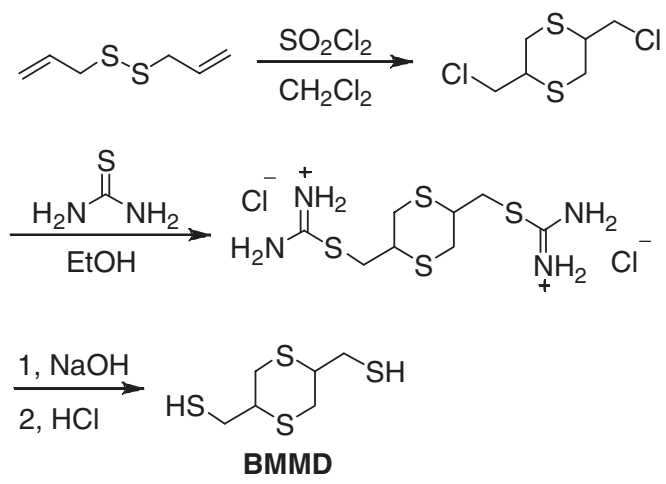

Scheme 1. Synthesis of BMMD. 

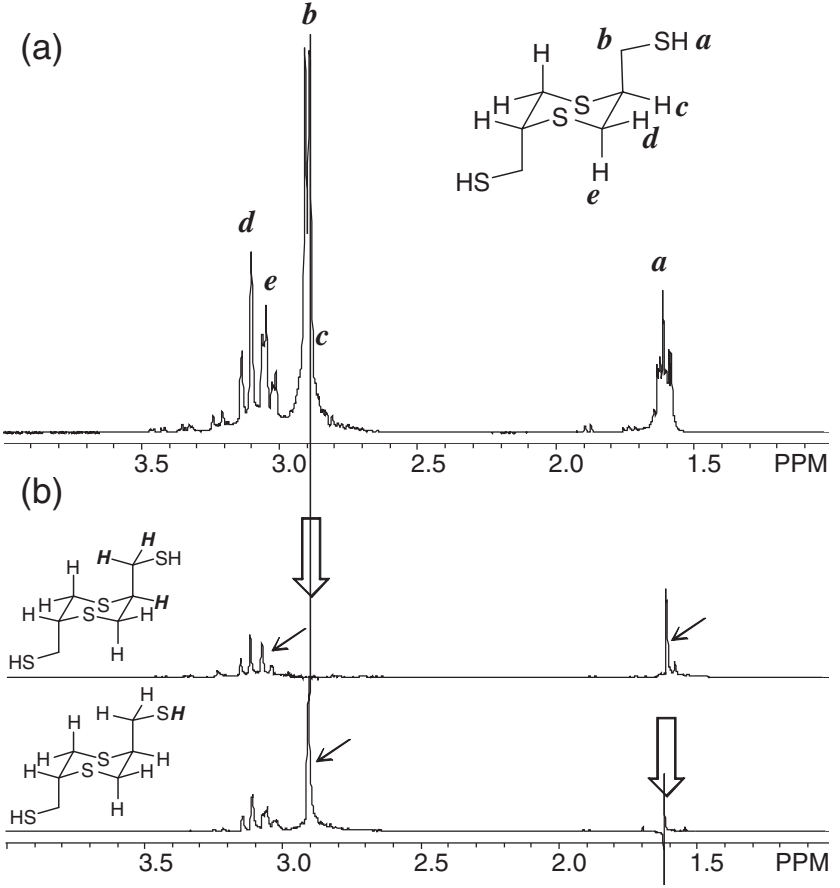

Figure 2. (a) ${ }^{1} \mathrm{H}$ NMR spectrum of BMMD. (b) ${ }^{1} \mathrm{H}$ NMR decoupling spectra of BMMD at 1.06 and $2.35 \mathrm{ppm}$.

$J=6.6 \mathrm{~Hz}$, were obtained, proton $c$ is absent in the axial direction. This increases the $J$ value, and otherwise the sulfanylmethyl group is in the axial direction. In order to confirm the above assignments, ${ }^{1} \mathrm{H}$ NMR decoupling measurement was performed (see Figure $2 b$ ). In the same way as the signals $\boldsymbol{b}$ and $\boldsymbol{c}$, the vicinal coupling between $\boldsymbol{a}$ and $\boldsymbol{e}$ disappears, leaving only germinal coupling of proton $\boldsymbol{a}$ by decoupling at $2.90 \mathrm{ppm}$. On the other hand, the coupling with only proton $\boldsymbol{b}$ disappeared by decoupling at $1.62 \mathrm{ppm}$. The assignments were thus corroborated based on these results, and BMMD was confirmed to consist of symmetric trans-isomers.

\section{Preparation and Characterization of Polymers}

Based on the preceding findings, DVS and BVSM were chosen as bis(vinyl sulfone) monomers (Scheme 2) because Michael polyaddition is one of the useful methods for preparing high-molecular-weight polymers.

The polymerization of DVS with BMMD was carried out at room temperature for $3 \mathrm{~h}$ in the presence of a catalytic amount of TEA as a basic catalyst in DMSO. Polymerization first proceeded in a homogeneous state and then with precipitation. The polymer thus obtained was a white solid and soluble in DMSO and hot NMP. The inherent viscosity of the polymer was $0.251 \mathrm{dL} / \mathrm{g}$.

On the other hand, TEA as a catalyst produced a gel in the polymerization of BMMD with BVSM probably because self Michael addition of BVSM occurred due to very acidic methylene protons between the two sulfone groups. To prevent this side reaction, a weaker base, pyridine was chosen as the basic catalyst. Moreover, a solution of BVSM in DMSO was
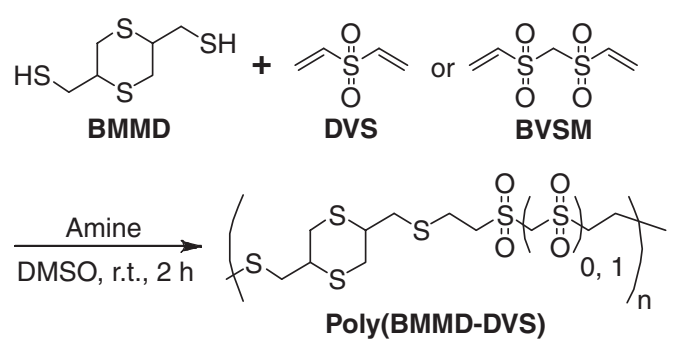

Scheme 2. Synthesis of poly(BMMD-DVS) and poly(BMMD-BVSM).

Table I. Synthesis of poly(BMMD-DVS) and poly(BMMD-BVSM)

\begin{tabular}{cccccccc}
\hline $\begin{array}{c}\text { Divinyl } \\
\text { compound }^{\mathrm{a}}\end{array}$ & $\begin{array}{c}\text { [Dithiol] } \\
/[\text { Divinyl] }\end{array}$ & Base & $\begin{array}{c}\text { Solvent } \\
(\mathrm{mL})\end{array}$ & $\begin{array}{c}\text { Yield } \\
(\%)\end{array}$ & $M_{\mathrm{n}}{ }^{\mathrm{b}}$ & $M_{\mathrm{w}} / M_{\mathrm{n}}{ }^{\mathrm{b}}$ & $\eta_{\text {inh }}{ }^{\mathrm{c}}$ \\
\hline DVS & 1 & TEA & 1 & 97 & $-^{\mathrm{d}}$ & $-^{\mathrm{d}}$ & 0.251 \\
BVSM & 1 & TEA & 2 & - & Gel & Gel & Gel \\
BVSM & 1.03 & Pyridine & 1 & 88 & Gel-like & Gel-like & Gel-like \\
BVSM & $1.03^{\mathrm{a}}$ & Pyridine & 2 & 77 & - & - & - \\
BVSM & $1.03^{\mathrm{a}}$ & Pyridine & 1 & 89 & 16300 & 1.62 & 0.137 \\
\hline
\end{tabular}

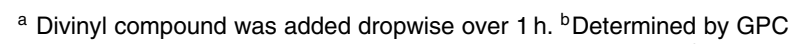
in DMF containing $0.01 \mathrm{M} \mathrm{LiBr}$ using polystyrene standard. ${ }^{\mathrm{C}}$ Inherent

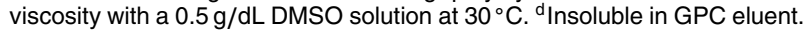

added dropwise to a solution of BMMD at room temperature, which successfully reduced the self Michael addition of BVSM. These results are summarized in Table I.

The polymer thus obtained was a white powder which was soluble in $N, N$-dimethylformamide (DMF), $N, N$-dimethylacetamide (DMAc), NMP, and DMSO at room temperature. The number average molecular weight $\left(M_{\mathrm{n}}\right)$ and the polydispersity of the polymer were 16,300 and 1.6 , respectively.

The structures of the polymers obtained were characterized by ${ }^{1} \mathrm{H}$ NMR and FT-IR spectroscopy, and elemental analysis. The IR spectra of the polymers exhibited absorptions at 1319 and $1111 \mathrm{~cm}^{-1}$ which are characteristic of the sulfone group. Figure 3 (bottom) shows the ${ }^{1} \mathrm{H}$ NMR spectrum of poly(BMMD-DVS). The signals of the monomer at 6.23 and $6.88 \mathrm{ppm}$ in the vinyl group were not observed, and the signal of the methylene protons adjacent to the sulfonyl group is clearly observed at $3.44 \mathrm{ppm}$. Poly(BMMD-BVSM) is also characterized by the ${ }^{1} \mathrm{H}$ NMR spectrum (Figure 3, top) in the same manner. The assignments of other protons are summarized in Figure 3.

\section{Thermal Properties}

High thermal stability is of strong importance for manufacturing optical components by injection molding. Previously, poly(DSDT-DVS) showed a relatively low 5\% weight loss temperature $\left(T_{5 \%}\right)$ of $275^{\circ} \mathrm{C}$ due to the thioacetal group. To improve the thermal stability, BMMD having a high sulfur content and no thioacetal group was selected. The thermal properties of poly(BMMD-DVS) are summarized in Table II. The $T_{5 \%}$ of $303^{\circ} \mathrm{C}$ is higher than that of Poly(DSDT-DVS) by ca. $30^{\circ} \mathrm{C}$ (see Figure 4). Unfortunately, poly(BMMD-BVSM) displayed the similar $T_{5 \%}$ value $\left(278^{\circ} \mathrm{C}\right)$ compared to poly- 


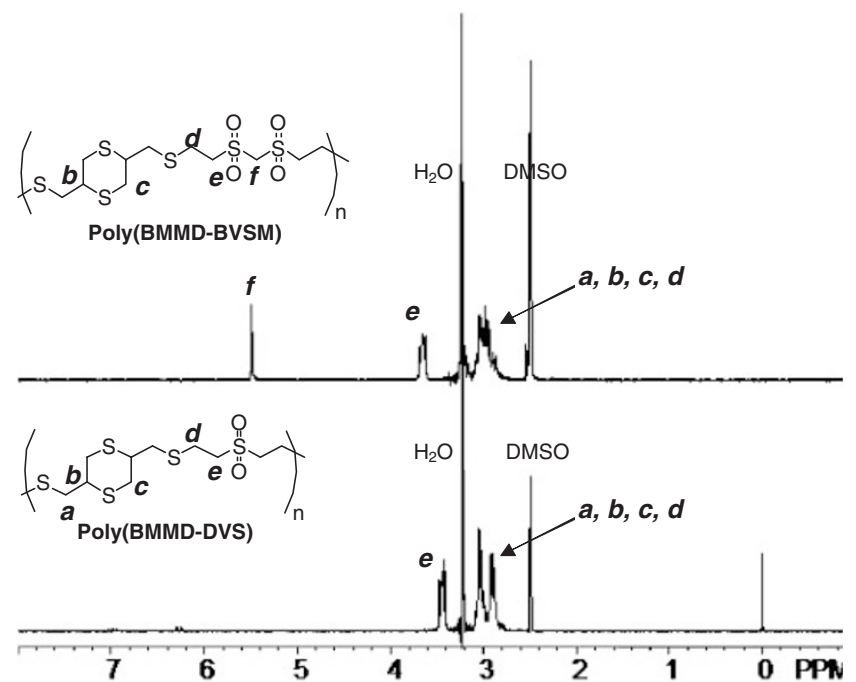

Figure 3. ${ }^{1} \mathrm{H}$ NMR spectra of poly(BMMD-DVS) and poly(BMMD-BVSM) in DMSO- $d_{6}$.

Table II. Thermal properties of the polymers

\begin{tabular}{ccccc}
\hline & $T_{5 \%}{ }^{\mathrm{a}}\left({ }^{\circ} \mathrm{C}\right)$ & $T_{\mathrm{c}}{ }^{\mathrm{b}}\left({ }^{\circ} \mathrm{C}\right)$ & $T_{\mathrm{m}}{ }^{\mathrm{c}}\left({ }^{\circ} \mathrm{C}\right)$ & $T_{\mathrm{g}}{ }^{\mathrm{d}}\left({ }^{\circ} \mathrm{C}\right)$ \\
\hline Poly(BMMD-DVS) & 303 & 119 & 174 & 47 \\
Poly(BMMD-BVSM) & 278 & - & - & 55 \\
\hline
\end{tabular}

${ }^{a} 5 \%$ weight loss temperature. ${ }^{b}$ Crystallization temperature. ${ }^{c}$ Melting temperature. ${ }^{\mathrm{d}}$ Glass transition temperature.

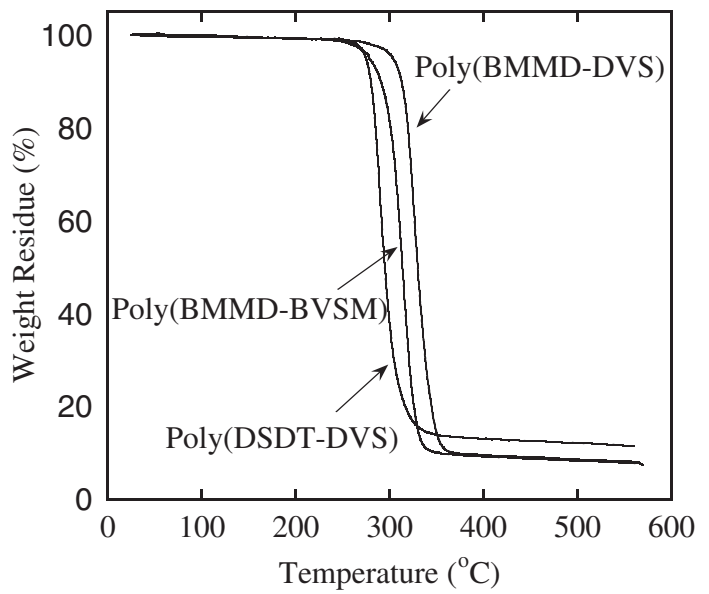

Figure 4. TGA curves of poly(BMMD-DVS), poly(BMMD-BVSM), and Poly(DSDT-DVS)

(DSDT-DVS) $\left(T_{5 \%}=275^{\circ} \mathrm{C}\right)$. This may be because of the thermally unstable methylene unit between two sulfone groups. However, both of poly(BMMD-DVS) and poly(BMMDBVSM) showed no coloration up to $200^{\circ} \mathrm{C}$ and slightly got colored over $200^{\circ} \mathrm{C}$, whereas poly(DSDT-DVS) showed a heavy coloration above $150{ }^{\circ} \mathrm{C}$ due to the thioacetal group. Figure 5 shows the DSC curves of poly(BMMD-DVS) and poly(BMMD-BVSM). The former is a semi-crystalline polymer with a glass transition temperature $\left(T_{\mathrm{g}}\right)$ of $47^{\circ} \mathrm{C}$, a crystallization temperature of $119^{\circ} \mathrm{C}$ and a melting point at 162

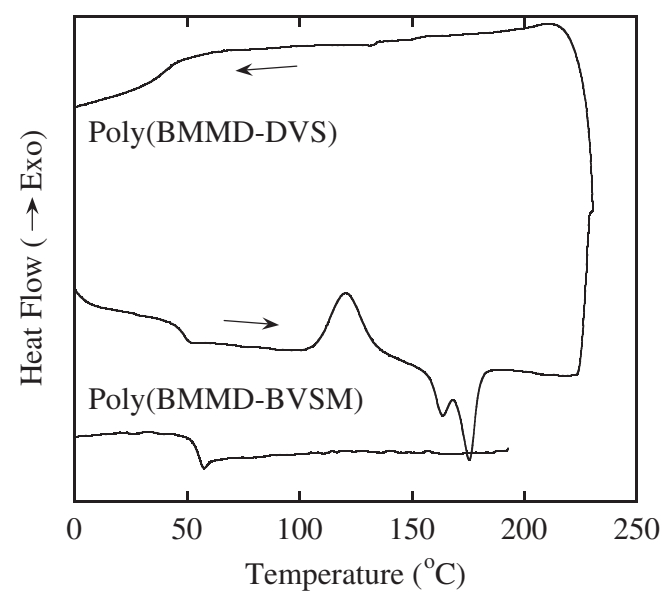

Figure 5. DSC curves of polymers (second heating and cooling).

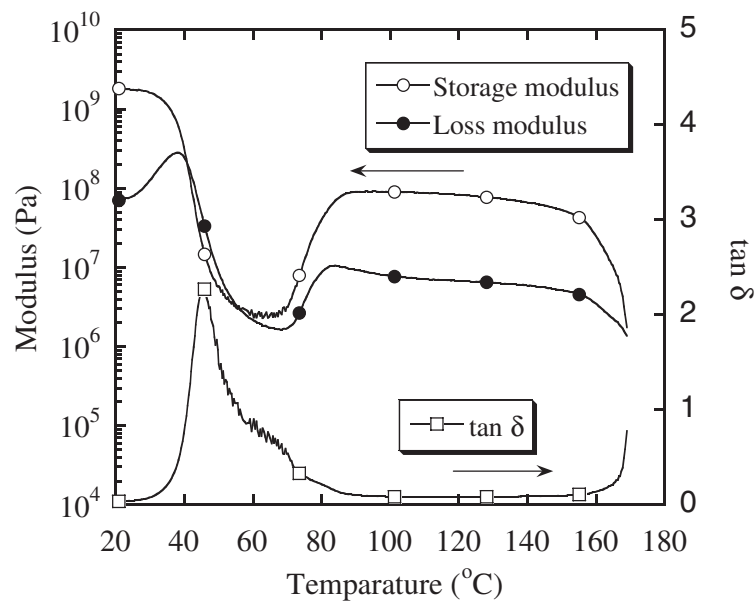

Figure 6. DMA curve of poly(BMMD-DVS) film

and $174{ }^{\circ} \mathrm{C}$. Although semi-crystalline polymers are not suitable for optical materials, the very slow crystallization rate of poly(BMMD-DVS) provides an amorphous polymer under normal cooling process, as shown in Figure 5. On the other hand, poly(BMMD-BVSM) is an inherently amorphous polymer with a $T_{\mathrm{g}}$ of $55^{\circ} \mathrm{C}$.

In Figure 6, the temperature dependence of the storage modulus $\left(E^{\prime}\right)$, loss modulus $\left(E^{\prime \prime}\right)$, and $\tan \delta$ of a poly(BMMDDVS) film are illustrated. These curves were obtained by DMA analysis. The film showed a high initial $E^{\prime}$ of $1.78 \mathrm{GPa}$ at $20^{\circ} \mathrm{C}$. The $E^{\prime}$ of the film decreases at around $T_{\mathrm{g}}\left(40^{\circ} \mathrm{C}\right)$, although the $E^{\prime}$ of $2 \mathrm{MPa}$ was maintained even at the minimum point. When the crystallization of poly(BMMD-DVS) starts from around $70{ }^{\circ} \mathrm{C}$, the $E^{\prime}$ recovers to $0.1 \mathrm{GPa}$. The $E^{\prime}$ drops rapidly again at the melting point of around $160^{\circ} \mathrm{C}$. From the DSC thermogram, the crystallization of poly(BMMD-DVS) starts at around $100^{\circ} \mathrm{C}$, which is higher than the crystallization temperature obtained by DMA. This is probably due to the very slow heating rate in DMA, though it was confirmed that the mechanical properties increased even at a low degree of crystallization. 


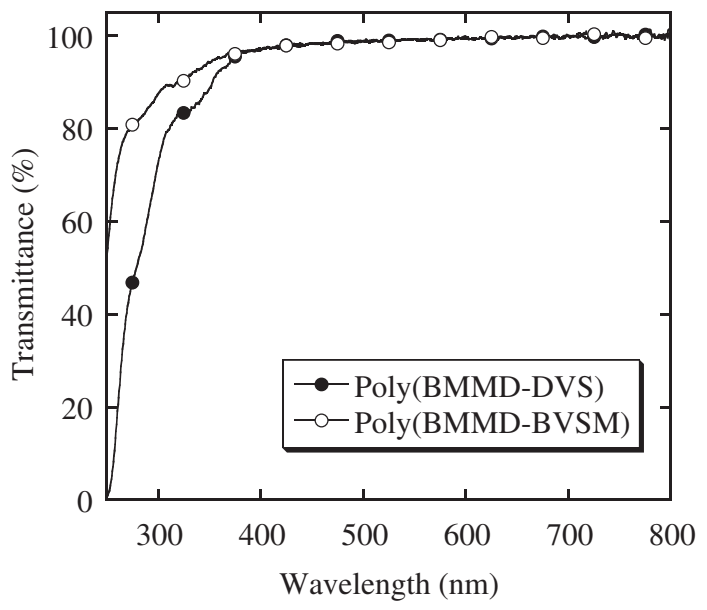

Figure 7. UV-vis spectra of films of poly(BMMD-DVS) $(26 \mu \mathrm{m}$-thick) and poly(BMMD-BVSM) $(18 \mu \mathrm{m}$-thick)

Table III. Optical properties of the polymers

\begin{tabular}{ccccccccc}
\hline Polymer & $\begin{array}{c}\text { Sulfur } \\
\text { content } \\
\text { (wt } \%)\end{array}$ & $n_{\mathrm{D}}{ }^{\mathrm{a}}$ & $n_{\mathrm{F}}{ }^{\mathrm{b}}$ & $n_{\mathrm{C}}{ }^{\mathrm{c}}$ & $v_{\mathrm{D}}{ }^{\mathrm{d}}$ & $n_{\infty}{ }^{\mathrm{e}}$ & $D^{\mathrm{e}}$ \\
\hline Poly(BMMD-DVS) & 48.5 & 1.6512 & 1.6627 & 1.6474 & 42.6 & 1.6236 & 7948 \\
Poly(BMMD-BVSM) & 47.1 & 1.6461 & 1.6574 & 1.6424 & 43.1 & 1.6283 & 8103 \\
ref-Poly(DSDT-DVS) & 53.0 & 1.6859 & 1.6961 & 1.6820 & 48.6 & 1.6647 & 7413 \\
\hline
\end{tabular}

a Measured at $589 \mathrm{~nm}$. bMeasured at $486 \mathrm{~nm}$. cMeasured at $633 \mathrm{~nm}$. ${ }^{d}$ Calculated using eq 1 . e Estimated from the curve fitting using the simplified Cauchy's formula.

\section{Optical Properties}

The UV-vis absorption spectra of the resulting polymer films with a thickness of $26 \mu \mathrm{m}$ (poly(BMMD-DVS)) and $18 \mu \mathrm{m}$ (poly(BMMD-BVSM)) are shown in Figure 7. Both poly(BMMD-DVS) and poly(BMMD-BVSM) exhibit high transparency in the visible region $(\lambda=400-800 \mathrm{~nm})$. The transmittance of these polymers at $400 \mathrm{~nm}$ is over $97 \%$ (without Fresnel reflection). The wholly aliphatic structure without $\pi$-electrons and the electron-withdrawing sulfone group make these polymers transparent and colorless.

The refractive indices and Abbe's numbers of the films are summarized in Table III. The wavelength dispersion of the refractive indices $\left(n_{\lambda}\right)$ thus obtained is plotted in Figure 8 with a fitted curve using the simplified Cauchy's formula.

$$
n_{\lambda}=n_{\infty}+D / \lambda^{2} \text {. }
$$

The refractive index at the infinite wavelength $\left(n_{\infty}\right)$ and the dispersion coefficient $(D)$ are also listed in Table III. The resulting polymers exhibit high refractive indices and high Abbe's numbers at the same time. The $\left(n_{\mathrm{D}}, v_{\mathrm{D}}\right)$ values of poly(BMMD-DVS) and poly(BMMD-BVSM) are (1.6512, 42.6) and (1.6461, 43.1), respectively. These values reach beyond "the limiting line." The refractive index of the polymers is increased by introducing sulfide groups $(-\mathrm{S}-)$ with a high atomic refraction. However, sulfur-containing polymers generally show relatively low Abbe's numbers. In contrast, the sulfonyl group $\left(-\mathrm{SO}_{2}-\right)$ effectively increases the Abbe's number because of the low molecular dispersion, as described

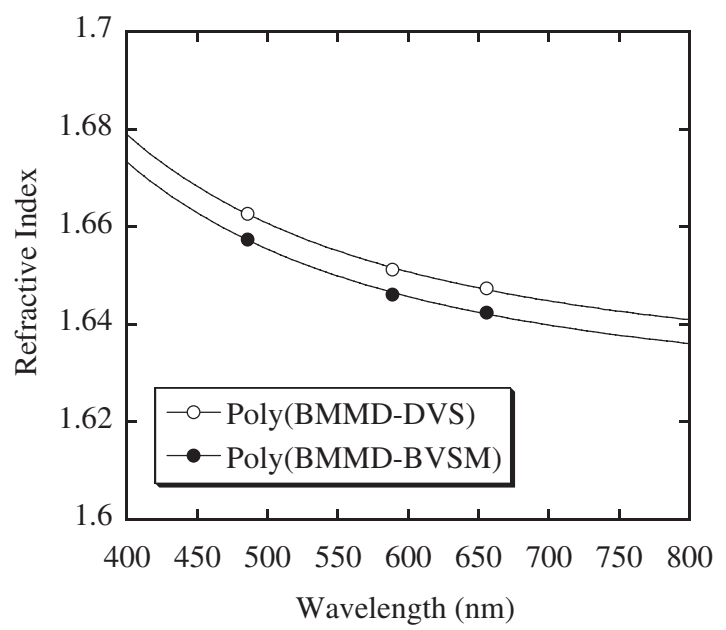

Figure 8. Wavelength dispersion of the experimental refractive indices of poly(BMMD-DVS) and poly(BMMD-BVSM). The dispersion is fitted by the simplified Cauchy's formula.

in the previous paper. ${ }^{15}$ Therefore, the combination of $-\mathrm{SO}_{2}-$ and $-\mathrm{S}$ - groups should be effective in increasing both the refractive index and Abbe's number.

Poly(BMMD-DVS) and poly(BMMD-BVSM) have one and two $-\mathrm{SO}_{2}-$ groups per repeating unit, respectively. As expected, poly(BMMD-BVSM) exhibits a higher $v_{\mathrm{D}}$ value due to the higher concentration of $-\mathrm{SO}_{2}-$. In contrast, poly(BMMD-DVS) with higher sulfur content exhibits a higher $n_{\mathrm{D}}$ value. In comparison with DSDT, the BMMD structure slightly reduces the $n_{\mathrm{D}}$ of the polymers, which is due to the lower sulfur content in the external methylene groups, but the significant improvement in thermal stability and mechanical properties of the BMMD-derived polymers at elevated temperatures are highly beneficial for injection molding of PES.

\section{CONCLUSION}

New thermoplastics, poly(thioether sulfone)s (PESs) with high refractive indices and high Abbe's numbers have been developed by the simultaneous introduction of sulfide, sulfone, and alicyclic units in the polymer chains. PESs with a high molecular weight were prepared by Michael polyaddition of 2,5-bis(sulfanylmethyl)-1,4-dithiane (BMMD) with divinyl sulfone (DVS) or bis(vinylsulfonyl)methane (BVSM). Poly(BMMD-DVS) and poly(BMMD-BVSM) respectively exhibited the high refractive indices of 1.6512 and 1.6461, and the Abbe's numbers of 42.6 and 43.1 as thermoplastics. The resulting polymers showed good resistance against thermal coloration even at $200{ }^{\circ} \mathrm{C}$, because the thioacetal skeletons are removed by the introduction of additional methylene groups to the DSDT structure.

Received: May 21, 2009

Accepted: June 30, 2009

Published: August 12, 2009 


\section{REFERENCES}

1. H. Ma, A. K. Y. Jen, and L. R. Dalton, Adv. Mater., 14, 1339 (2002).

2. M. Pagliaro and R. Ciriminna, J. Mater. Chem., 15, 4981 (2005).

3. L. W. Shacklette, Opt. Photonics News, 15, 22 (2004).

4. C. Gao, B. Yang, and J. Shen, J. Appl. Polym. Sci., 75, 1474 (2000).

5. T. Matsuda, Y. Funae, M. Yoshida, T. Yamamoto, and T. Takaya, J. Appl. Polym. Sci., 76, 50 (2000).

6. T. Kohara, Macromol. Symp., 101, 571 (1996).

7. M. L. Rubin, Surv. Ophthalmol., 30, 321 (1986).

8. H. Morishiri and S. Kobayashi, Jpn. Kokai Tokkyo Koho, 2005, JP 2005325274.

9. H. Morishiri and S. Kobayashi, Jpn. Kokai Tokkyo Koho, 2006, JP 2006131724 .
10. R. Okada, T. Ohkubo, and M. Kosaka, Eur. Pat. Appl., 1993, EP 530757.

11. H. Dislich, Angew. Chem., Int. Ed., 18, 49 (1979).

12. T. Okubo, S. Kohmoto, and M. Yamamoto, J. Macromol. Sci., Part A: Pure Appl. Chem., 35, 1819 (1998).

13. H. Dislich, Angew. Chem., 91, 52 (1979).

14. C.-J. Yang and S. A. Jenekhe, Chem. Mater., 7, 1276 (1995).

15. R. Okutsu, Y. Suzuki, A. Shinji, and M. Ueda, Macromolecules, 41, 6165 (2008).

16. H. Dislich and A. Jacobsen, Angew. Chem., Int. Ed., 12, 439 (1973).

17. T. Okubo, S. Kohmoto, and M. Yamomoto, J. Mater. Sci., 34, 337 (1999).

18. T. Okubo, S. Kohmoto, and M. Yamomoto, J. Appl. Polym. Sci., 68, 1791 (1998). 